\title{
Examining Accessibility and Reliability in the Evolution of Subway Systems
}

\author{
Hyun Kim \\ University of Tennessee \\ Yena Song \\ Chonnam National University, Korea
}

\begin{abstract}
The subway system in the city of Seoul has dramatically evolved from a single subway line of less than $10 \mathrm{~km}$ in the early 1970s to one of the largest mass transit systems in the world, with more than 13 lines and 400 stations in 2014. This study aims to explore longitudinal changes in network accessibility and reliability in relation to the four evolutionary stages of the Seoul subway system (1979, 1985, 2001, and 2014). With rapid expansion of the network, accessibility and reliability have improved over time, but at a different pace and with different spatial patterns. The accessibility level has consistently increased, along with the core-to-periphery improvement spatial pattern, while reliability has been quickly enhanced as a result of the completion of a circular line in the second stage and stabilized early since the third stage. This study contributes to the field of transport network planning, in which well-balanced network functionality is a critical concern.
\end{abstract}

\section{Introduction}

The evolution of a public transportation system reflects the interplay of demography, economic development, and transportation needs over time, and mass transit systems are one of the most crucial elements in the evolution of cities and the dynamic processes that take place in them (Bettencourt et al. 2007; Niedzielski and Malecki 2012). Public transportation serves the development and growth of denselypopulated metropolitan areas by facilitating labor movement from outside or within the metropolitan area with better accessibility (Lakshmanan et al. 2009). Better public transportation networks lower travel times and the travel costs of the individuals who use the networks, giving them more options for their trips and also enabling them to move further out of central areas in relation to housing or work options, which is directly related to land development in areas once considered unreachable (Lakshmanan and Anderson 2002, 2005; Lucas 2006). As such, improving accessibility 
for all has been a focus of public transport planning. However, accessibility measures are concerned little with network reliability, which refers to how well the network is systematically organized to continue its operation at a desired level in the face of possible operational failures of nodes or links. Maintaining the system's reliability at a desired level is as important as accessibility on the supply side because disruptions of mass transit systems can have severe adverse socio-economic impacts, along with degradation of network accessibility (D'Este and Taylor 2003). Furthermore, failure in a station can lead to cascading failures in the whole network system, raising issues about the resilience of the system (Nicholson and Dalziell 2003; Kim et al. 2015). The level of reliability is associated more with how many alternative routes are available than how efficiently flows are delivered at lower costs or shorter distance, which is the key factor determining the nodal accessibility ( $D^{\prime}$ Este and Taylor 2003). Therefore, assessing existing network performance by considering both criteria is critical, as networks need to meet both demand and supply requirements.

Since it commenced operation in 1974, the Seoul subway system has expanded its size and the spatial extent of service by continually adding new stations and lines to accommodate the increasing public transportation demand and to support the activities in the expanded metropolitan area. The expansion of networks shows how spatially and temporally both accessibility and reliability of the system are improved to reflect economic development. For example, the southern area of Seoul, historically an underdeveloped area, experienced a considerable increase in the concentration of the population with the emergence of new Central Business Districts (CBDs) in Yeongdeungpo-Gu and Gangnam-Gu in the southern parts of Seoul as the first circular line, Line 2, was established in these areas in the late 1970s. The establishment of Line 2 involved constructing a handful of stations and resulted in considerable accessibility enhancement in the south of Seoul. On the other hand, the subway lines in Seoul occasionally have experienced unexpected delays or extreme congestion because of malfunctions resulting from natural disasters (e.g., flooding), train crashes, and transit strikes, as well as operational issues, including periodic maintenance (Zhu and Levinson 2012; Kim et al. 2015). Between 2008 and 2013, 11 critical accidents were reported on the Seoul subway system; these resulted in considerable socio-economic costs and recovery costs relating to the disruptions (ARAIB 2015). Such aspects can be assessed in terms of reliability.

This study aims to adopt a longitudinal point of view by exploring the changes in network accessibility and reliability following the evolution of the subway system in Seoul. Our empirical study involves three steps-1) defining both measures suitable for assessing a subway system; 2) examining changes in network characteristics at global and nodal levels; and 3) providing a set of results to highlight the characteristics of the evolution-followed, by way of conclusion, with a summary of the policy implications.

\section{Evolution of the Subway System in Seoul}

Seoul, the capital city of South Korea, is one of the largest and most densely-populated cities in the world, generating a large volume of trips and travel demand. This requires well-developed public transportation systems since private travel modes cannot 
accommodate the high demand effectively and can cause serious adverse effects such as congestion, pollution, and degraded public health within the area. Based upon the time trends in terms of number of passengers and addition of new lines, Song and Kim (2015) have divided the temporal expansion of the Seoul subway network into four stages: stage 1 (1974-1979), stage 2 (1979-1985), stage 3 (1985-2001), and stage 4 (20012014). Figure 1 shows the evolution of the subway network in relation to the location of CBDs. The old CBD area has functioned as the core of the capital city in terms of both economics and politics; the new CBD area began to be developed in the late 1970s; and the third CBD is the financial center (Song et al. 2012).

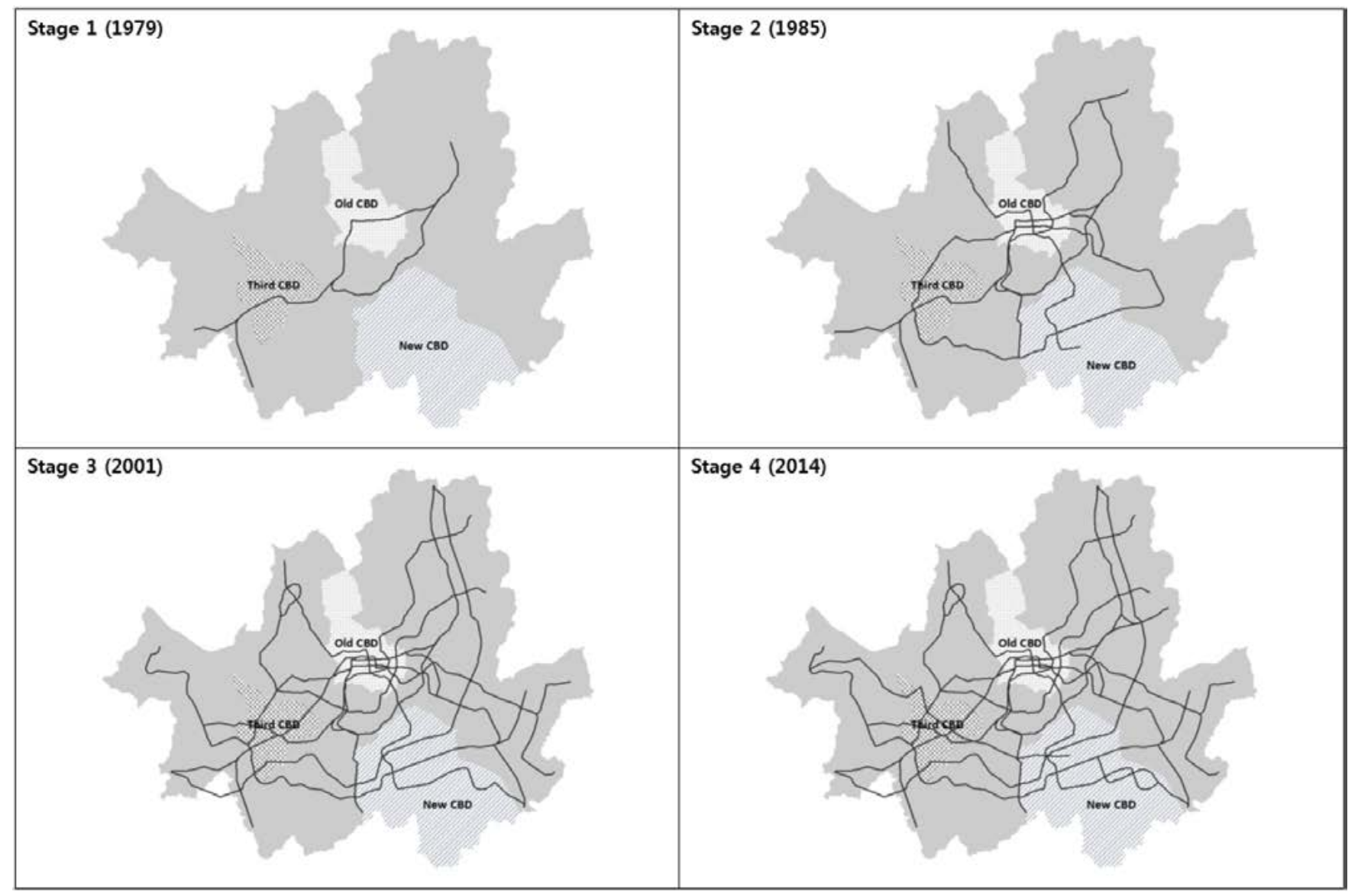

FIGURE 1. Evolution of Seoul subway network

This division is supported by an early classification of the evolution of the Seoul subway system suggested by Lee and Lee (1998). In the first stage, the first subway line began to operate. Before that point, the public in Seoul had been very dependent upon the bus system to get around the city (Pucher et al. 2005). In the beginning, the Seoul subway had only one underground line, of less than $10 \mathrm{~km}$, with a $6 \%$ modal share, and the bus was still the major mode chosen by the public. A noteworthy expansion occurred during stage 2, with a circular line (Line 2) being added to the existing linear form of the subway system, providing passengers with increased alternative routing 
choices and resulting in the subway becoming the most frequently-used travel mode in Seoul as a consequence (Lee and Lee 1998). As presented in Table 1, after 1996, more than $30 \%$ of modal share was achieved by the subway, absorbing the share of buses. This achievement was possible because the penetration of some new lines enabled the network to serve the dense peripheral residential areas through stage 3. By 2012, the subway system's total network length had expanded to $327 \mathrm{~km}$ and was ranked fifth in the world (The Economist, 2013), and its modal share was more than $36 \%$ of all passenger journeys in 2010. Currently, there are 17 lines in operation in Seoul and its vicinity, and further expansion is expected.

TABLE 1.

Passenger Travel Modal Share in Seoul

\begin{tabular}{|c|l|r|c|r|r|r|r|}
\hline \multirow{2}{*}{ Year } & $\begin{array}{l}\text { Share by } \\
\text { Mode }\end{array}$ & $\begin{array}{c}\text { Private } \\
\text { Car }\end{array}$ & \multicolumn{1}{c|}{ Bus } & Subway & Taxi & Others & Total \\
\hline \multirow{2}{*}{1996} & Trips* & 6,829 & 8,358 & 8,183 & 2,901 & 1,529 & 27,800 \\
\cline { 2 - 8 } & Share (\%) & 24.6 & 30.1 & 29.4 & 10.4 & 5.5 & 100 \\
\hline \multirow{2}{*}{2002} & Trips* & 7,983 & 7,705 & 10,285 & 2,195 & 1,513 & 29,680 \\
\cline { 2 - 8 } & Share (\%) & 26.9 & 26.0 & 34.6 & 7.4 & 5.1 & 100 \\
\hline \multirow{2}{*}{2006} & Trips* & 8,188 & 8,616 & 10,839 & 1,959 & 1,592 & 31,196 \\
\cline { 2 - 8 } & Share (\%) & 26.3 & 27.6 & 34.7 & 6.3 & 5.1 & 100 \\
\hline \multirow{2}{*}{2010} & Trips* & 7,502 & 8,746 & 11,289 & 2,236 & 1,382 & 31,155 \\
\cline { 2 - 8 } & Share (\%) & 24.1 & 28.1 & 36.2 & 7.2 & 4.4 & 100 \\
\hline
\end{tabular}

*Unit = thousands of trips per day.

Source: SMG 2014

The main purpose of network evolution is to maintain a good quality subway network and to provide an efficient and effective travel mode to the general public. As Lakshmanan et al. (2009) argued, based on their case study of New York City, economic and social activities in a densely-populated metropolis cannot be sustained without public transit systems. With the advent of rapid urban sprawl during the last few decades, a large proportion of the workforce now live far from their workplaces, and the majority rely on public transport for their work and business journeys. Kim and Zhang (2005) and Lee et al. (2010) also provided evidence from case studies on Seoul that show that accessibility is positively associated with commercial land rent and residential rent, such as housing value, in accordance with other international studies (Cervero and Duncan 2002; McMillen and McDonald 2004; Weinberger 2001). However, with increased dependency on mass transit systems, the system's reliability becomes another critical factor that affects socio-economic activities because congestion, delays, and incidents resulting from operational failure and human errors affect the accessibility itself, as do travelers' perceptions regarding the uncertainty of accessibility (Bell and Cassir 2000; Reggiani 2013; Kim et al. 2015). 


\section{Methodology \\ Accessibility Measurement}

Although there is no consensus on the definition of accessibility, and numerous measures have been defined and used for specific research contexts (for an extensive review, refer to Reggiani 1998; Halden et al. 2005; Páez et al. 2012), generally, aaccessibility refers to the reachability of goods, services, activities, and destinations, which often is translated into a level of opportunities for potential interaction among demand (Hansen 1959; Harris 2001). The main idea is centered on the demand aspect, which represents people's overall ability or opportunity to reach spatially-distributed services and activities, and measurement of the ease of their access (Harris 2001). Páez et al. (2012) suggested that many accessibility measures have two basic components: travel cost and quality or quantity of opportunities. This argument can be applied to those studies concerned with land use or regional planning. On the other hand, an approach that looks into the cost factors only, without taking account of the opportunities, is preferred when changes in network characteristics or the evolution of a network is the central subject to be investigated (Garrison 1960; Gould 1967; Tinkler 1972).

This study intends to measure the changes in subway accessibility at both stations and the entire system level over four stages and concentrates only on transport networks themselves. Unlike most recent accessibility studies - which tend to be overly complex and try to capture the impacts of other factors rather than the network itself-to characterize the change in a consistent manner, this study is concerned only about network accessibility based upon travel cost.

The accessibility of each station $\left(A_{i}^{\text {node }}\right)$ is measured using the physical distances between station pairs, as shown in Equation 1, which enables us to focus on the network itself and thereby to facilitate the comparison with reliability measures.

$$
A_{i}^{\text {node }}=k \sum_{j, i \neq j}^{N} \frac{1}{d_{i j}}
$$

Where,

$$
\begin{aligned}
& N=\text { number of stations }(N=1 \text { to } n) \\
& k=\text { scaling constant }\left(=10^{2}\right) \\
& d_{i j}=\text { network-based physical distance between station } i \text { and } j
\end{aligned}
$$

$k$ is a scaling constant, which is used to make the results more readable; $10^{2}$ is used. Distances between origin and destination pairs were calibrated to obtain the shortest travel distances. An inverse distance sum was used in the calculation. The higher $A_{i}$ indicates higher accessibility, i.e., shorter distance is covered to reach potential destinations from station $i$. 


\section{Reliability Measurement}

Reliability is widely used to assess a network's robustness when either the empirical or hypothetical operational probability of a network component is known (Colbourn 1987; Kim et al. 2015), and this is commonly expressed as the operational probability of a network carrying out its stated mission satisfactorily for a certain period of time (Yoo and Deo 1988; Dhillon 2011; Kim et al. 2015). The potential degradation of the reliability of a network can be due to a variety of reasons, ranging from inconveniences such as scheduled maintenance to an excessive concentration of flows at nodes (stations or terminals) or links (subway lines or railways). It includes unexpected accidents such as natural disasters and intended attacks. The outcome includes delays in delivering flows in the network, shut-down of stations or subway lines and even intangible socioeconomic costs. The concept of network reliability has been applied to examine the network resilience of transport networks or spatial economic infrastructure (e.g., Cox et al. 2011; Murray and Grubesic 2007; Matisziw et al. 2009; Murray et al. 2008; Nagurney and Qiang 2009; Reggiani 2013; Schintler et al. 2007). Less reliable areas and subway stations are more likely to discontinue their operation and incur potential disruptions (Allenby and Fink 2005). To identify the reliable or unreliable areas, first we need to measure a station's reliability, named nodal reliability $R_{i}^{\text {node }}$. To do this, equation (2) is used to calculate route reliability from $i$ to $j$, followed by equation (3), which is used to compute $R_{i}^{\text {node }}$. Suppose that the operational probability (i.e., on-time performance or delay rate) of a link connecting two nodes $p(e)$ is known [i.e., $0 \leq p(e) \leq 1$ ]. Here, $p(e)$ is translated as the probability that any passenger flow from a station to the next station by the link can be delivered without there being any malfunction or delay. Let $r_{i j}$ be the route reliability for a pair of stations, $i$ and $j$, in subway system $G$, which is calculated using the sum of reliability for $k$ number of disjoint paths $\left(D_{k}\right)$ between $i$ and $j$. A disjoint path $D_{k}$ is effectively enumerated based on the logic of the Boolean algebra method to the available paths $E_{q}$ for a pair of $i-j$. The path reliability $p\left(E_{q}\right)$ is calculated using $p\left(E_{q}\right)=\prod_{i=1(i \in Q)} p\left(e_{i}\right)$, where $Q$ is the set of links $e_{i}$ constituting the path $E_{q}$ (for these procedures in detail, see Yoo and Deo 1989).

$$
r_{i j}(G, p)=\sum_{k=1} p\left(D_{k}\right)=\sum_{k=1}^{m}\left[\prod_{q=f}^{r} p\left(\bar{E}_{q-1}\right) \cdot p\left(E_{q}\right)\right]
$$

Where,

$$
\begin{aligned}
p\left(D_{k}\right)= & \text { the reliability for a disjoint path } D_{k} \text { from the identified available paths } E_{q} \text { for } \\
& \text { a pair of } i-j,(k=1 \text { to } m) \\
p\left(E_{q}\right)= & \text { the reliability of an identified available path } E_{q} \text { for a pair of } i-j, Q \text { is the set of } \\
& \text { links } e_{i} \text { consisting a path } E_{q} \\
p\left(\bar{E}_{q}\right)= & \text { the complementary probability for } p\left(E_{q}\right)
\end{aligned}
$$


Then, using equation (3), $R_{i}^{\text {node }}$, the nodal reliability of station $i$, which is the average reliability in relation to all other stations $j$, is calculated.

$$
R_{i}^{\text {node }}(G, p)=\frac{1}{N} \sum_{j=1}^{n} r_{i j}
$$

Where $R_{i}(G, p)$ is the nodal reliability of station $i$, which defines the average reliability from station $i$ to other stations $j$, where reliability $p$ at link is known on network $G$.

This concept of $R_{i}^{\text {node }}$ has been employed in public transit or rail networks (Michael 2000; Vromans et al. 2006; Kim et al. 2015). Higher $R_{i}^{\text {node }}$ at station $i$ indicates that the station is highly reachable from other nodes without delay or failure most of the time. In general, the more paths that are available from other nodes $j$ to node $i$, the higher nodal reliability node $i$ has.

Basically, accessibility is represented as a form of index. This is useful for comparing the level of accessibility. However, the range of the index is dependent upon what measure is used. For example, the simplest form of accessibility measure is to use the number of direct and indirect paths at a station to other nodes based upon connectivity (i.e., connected or not connected). Alternatively, time distance or the opportunity costs between origin-destination pairs can be used for $d_{i j}$. However, for this case, the range of values cannot be well defined unless the calculation method is standardized. In contrast, reliability measures typically employ a probability, ranging from 0.0 to 1.0 , to represent the operational success or failure among nodes. Thus, the reliability measure is easy to interpret and enables comparison among different networks.

\section{Data}

Given the four categories of evolutionary stages by Song and Kim (2015), we constructed the subway networks based on the subway network map at the end of each stage (i.e., 1979, 1985, 2001, and 2014). The station information is available at a public website, Korea Transport Database (www.ktdb.go.kr), in the form of point data. With the positional information provided by the public agency, the links were digitized to construct the network in a geographic information system (GIS) environment. Then, $A_{i}^{\text {node }}$ was measured based upon the shortest physical network-based distance among stations $i$ and $j$ from the network maps.

To compute $R_{i}^{\text {node }}$, two matrices-an incidence matrix and an on-time performance matrix-were used for each link between stations $i$ and $j$. Incidence matrix consists of $[0,1]$, to represent the connectivity by links among nodes. For the on-time performance matrix, this study used hypothetical on-time performance data with $p(e)=0.9$ for all links in the reliability computation process because the empirical data of the Seoul subway system is not available for the stages. Note that this value is the commonly-accepted link on-time performance data in which empirical reliability data are not available for networks (Yoo and Deo 1988; Kim et al. 2015). 


\section{Analysis Results \\ Global Change of Accessibility and Reliability}

Figure 2 presents three indices: the averages of nodal accessibility and reliability and the number of stations on the network at the end of each stage. For comparison, the values were standardized by reference to the year 1985 (1985=1.0). All three indices increase, but they do so at different rates at each stage, highlighting a different curve of maturity with network evolution. The number of subway stations increased nearly 10 times between $1979(n=28)$ and $2014(n=271)$. Along with a rapid expansion of the system, the averaged nodal accessibility increased by 5.6 times. However, network reliability was enhanced by only 1.6 times during the same period. In particular, the network experienced a significant improvement in reliability when it moved from stage 1 (0.661) to stage $2(=1.0)$, but did not improve much when moving to stage $3(=1.017)$ and even to the fourth stage $(=1.11)$, indicating that the reliability of the Seoul subway system quickly matured when the evolution entered stage 2 but remained fairly stable through stages 3 and 4 . In contrast, network accessibility significantly improved at both stages 3 and 4. During the same period, the annual ridership of the system increased rather consistently and rapidly -approximately 200 million in 1979, 500 million in 1985, 1 billion in 2000, and 1.8 billion in 2014.

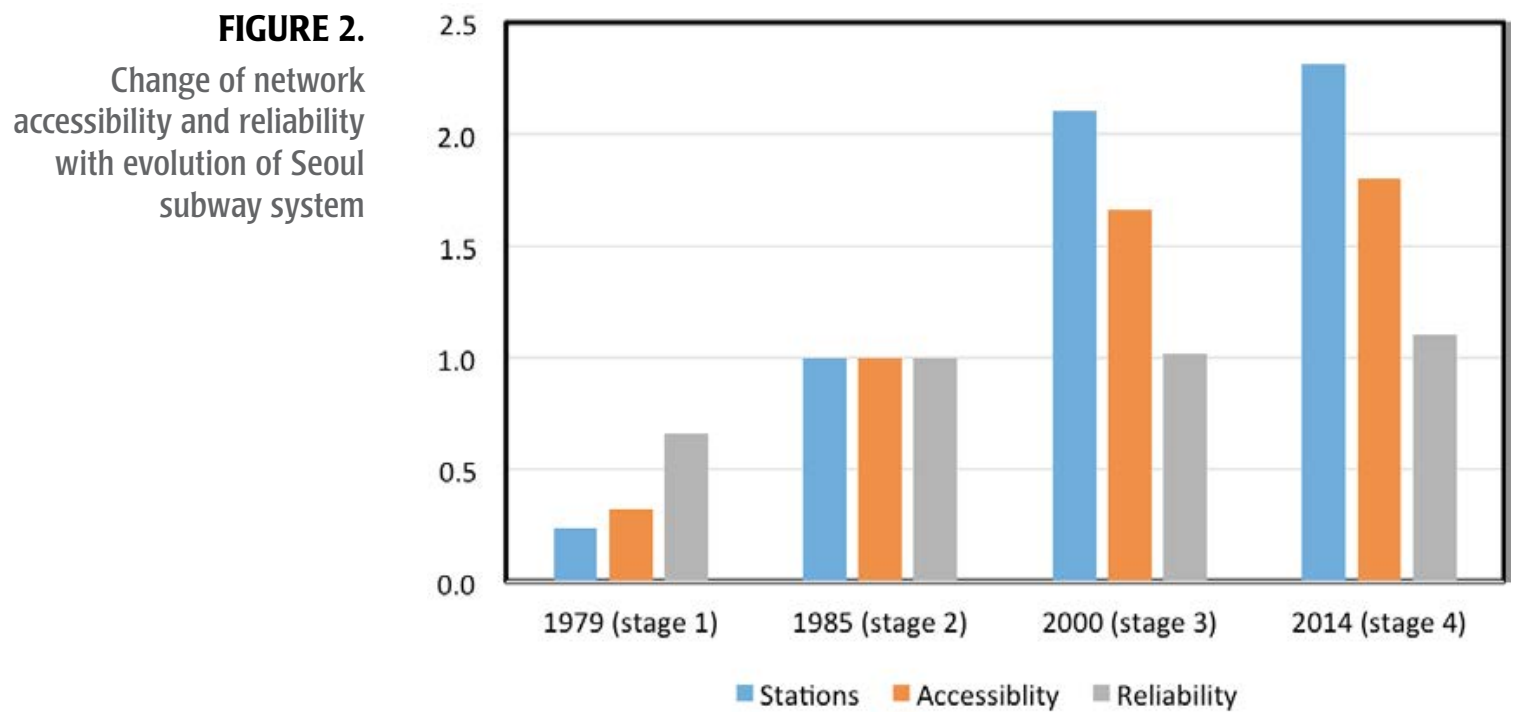

Note: Figures are relative to 1985 values.

To further investigate the association between two measures, the frequency distributions (unit: \%) of nodal accessibility (3-a) and reliability (3-b) are presented in Figure 3. Notice that the overall distribution of both measures has moved towards the right-hand side, i.e., accessibility and reliability increased over time. However, accessibility improves with the steady progress of each stage, maintaining a bell-shaped distribution in relation to the stages (except the first stage, 1979). In contrast, nodal reliability quickly skewed right after stage 2 , and this tendency is more distinguished in stage 4, suggesting that the critical transition had already been made between stages 1 
and 2 and stabilized at a "high" network reliability status since then. The main reason for the considerable enhancement of the reliability at stage 2 was the completion of the "circular" line (Line 2), which enabled more alternative routes to be possible in the system. Figures 2 and 3 together imply that the evolution of the Seoul subway system has been asymmetrical as regards accessibility and reliability.
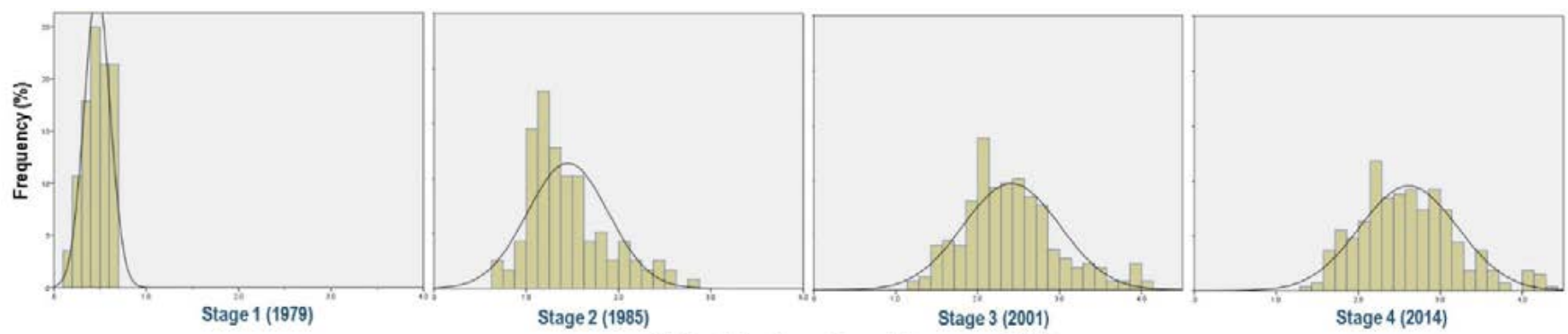

a) Distribution of nodal accessibility

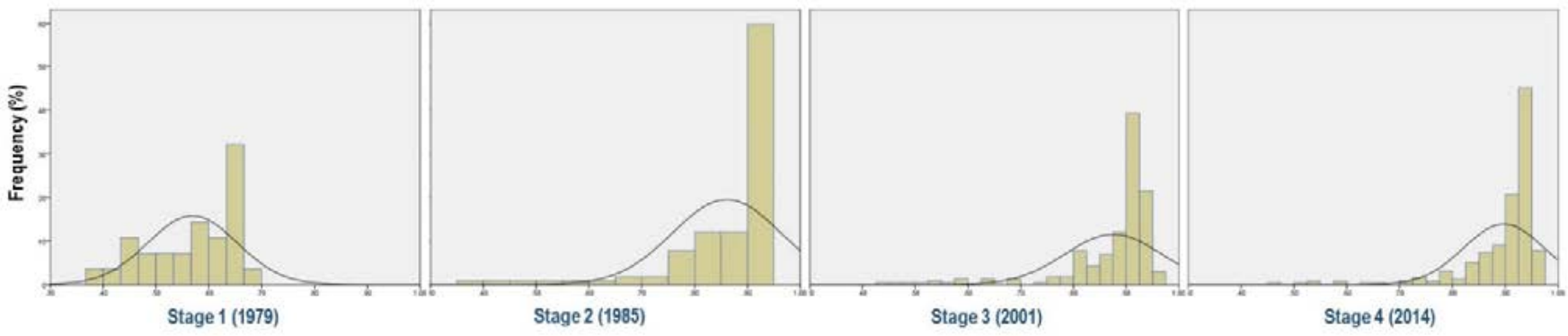

b) Distribution of nodal reliability

FIGURE 3. Distributions of (a) nodal accessibility and (b) reliability at four stages

\section{Changes in Nodal Accessibility and Reliability}

Although accessibility and reliability are derived from the same root, which focuses on the performance of nodes based on network topology, and results in an increase of values overall with increased network complexity over time, this does not necessarily entail that the two measures are positively and strongly associated at the individual station level with network evolution. Table 2 clearly shows that the relationship between the two measures has not been strongly correlated. In the early stage (1979) of subway expansion, no significant correlations were observed, but both measures have positive correlations at the end of the second, third, and fourth stages. However, the strength is not improved consistently, as stage 4 has a diminished correlation, implying that some stations experience unbalanced improvements of accessibility and reliability while the structure of the network has been complicated with added stations and links. This fact raises the issue of how network evolution affects accessibility and reliability at node level from a geographic perspective. 
TABLE 2.

\begin{tabular}{|c|c|c|c|c|}
\hline $\begin{array}{c}\text { Type of Correlation / } \\
\text { Year }\end{array}$ & $\begin{array}{c}\text { Stage 1 } \\
1979(n=28)\end{array}$ & $\begin{array}{c}\text { Stage 2 } \\
1985(\boldsymbol{n}=117)\end{array}$ & $\begin{array}{c}\text { Stage 3 } \\
2001(\boldsymbol{n}=246)\end{array}$ & $\begin{array}{c}\text { Stage 4 } \\
2014(\boldsymbol{n}=271)\end{array}$ \\
\hline Pearson's $r$ & -0.037 & $0.390^{*}$ & $0.501^{*}$ & $0.445^{*}$ \\
\hline
\end{tabular}

${ }^{*}$ Note: $p$-value $<0.01$.

The outlier stations observed at $95 \%$ confidence interval $(\mathrm{Cl})$ in the linear regression model between two measures were identified at the end of the subway networks and characterized as stations with either extremely low values of reliability or accessibility. However, their locations changed at each stage. For example, in stage 2, six outlier stations are located at the northern end of the newly established Line 3, while in stage 3 six outlier stations are identified at the eastern end and five other outlier stations are at the western end of Line 5 . The stations at the end of subway lines or newly-added lines are more difficult to access than other existing stations, but their rankings in both measures changed quickly with the network's evolution.

Table 3 and Figure 4 present the top-10 stations and their locations in terms of the accessibility and reliability rankings. Clearly, consistency in ranking within each measure across the stages is observed, but the rankings are not similar between measures, which strongly indicates that different geographical surfaces of accessibility and reliability are formed at each stage. Highly-accessible stations are found in the central area, and the rank did not change much over time. Considering stages 2, 3, and 4 in Table 3, nearly $90 \%$ of high-accessibility stations were transfer stations and only $50 \%$ of high-reliability stations were identified as transfer stations. Such findings support the fact that the spatial patterns and properties of the two measures do not necessarily correspond to each other, despite their positive correlation. Interestingly, all stations listed as top-10 stations in terms of accessibility are located in the northern part of Seoul, whereas 35\% of the top-10 stations in terms of reliability are on the southern part of the Han River. Historically, the old CBD was located in the northern part of the city, from which the city has grown out in all directions. The southern part of the city has undergone faster development by adding lines at later stages (Song et al. 2012). 
TABLE 3. Stations with the Highest Accessibility and Reliability

\begin{tabular}{|c|c|c|c|c|c|c|c|c|}
\hline \multicolumn{5}{|c|}{ Accessibility } & \multicolumn{4}{|c|}{ Reliability } \\
\hline Rank & 1979 & 1985 & 2001 & 2014 & 1979 & 1985 & 2001 & 2014 \\
\hline 1 & Jongro-5ga & Uljiro-3ga & Uljiro-3ga & Uljiro-3ga & Seoul Station & Seoul Nat'l Univ of Edu & Nowon & Nowon \\
\hline 2 & Dongdaemun & Chungmuro & $\begin{array}{l}\text { Dongdaemun } \\
\text { Park }\end{array}$ & $\begin{array}{l}\text { Dongdaemun } \\
\text { Park }\end{array}$ & Namyeong & Seocho & $\begin{array}{l}\text { Chang- } \\
\text { dong }\end{array}$ & $\begin{array}{c}\text { Chang- } \\
\text { dong }\end{array}$ \\
\hline 3 & Jongro-3ga & Jongro-3ga & Sindang & Sindang & Yongsan & Sadang & Dobongsan & Suseo \\
\hline 4 & Jonggak & Uljiro-4ga & Dongdaemun & Dongdaemun & Oryu-dong & Bangbae & Banghak & Gunja \\
\hline 5 & Hoegi & Dongdaemun & Cheonggu & Cheonggu & City Hall & Gangnam & Gunja & Banghak \\
\hline 6 & Jegi-dong & Dongdaemun Park & Dongmyo & Dongmyo & Noryangjin & Yeoksam & Dobong & Dobongsan \\
\hline 7 & Cheongrangni & Jongro-5ga & Chungmuro & Chungmuro & Gaebong & Konkuk Univ & Madeul & Daecheong \\
\hline 8 & Sinseol-dong & Uljiro-1ga & Jongro-3ga & Jongro-3ga & Guro & Ichon & Junggye & Irwon \\
\hline 9 & City Hall & Myeong-dong & Uljiro-4ga & Uljiro-4ga & Daebang & Seongsu & Taereung & Dobong \\
\hline 10 & Hankuk Univ. & City Hall & Yaksu & Yaksu & Jonggak & Guui & Suraksan & Taereung \\
\hline
\end{tabular}

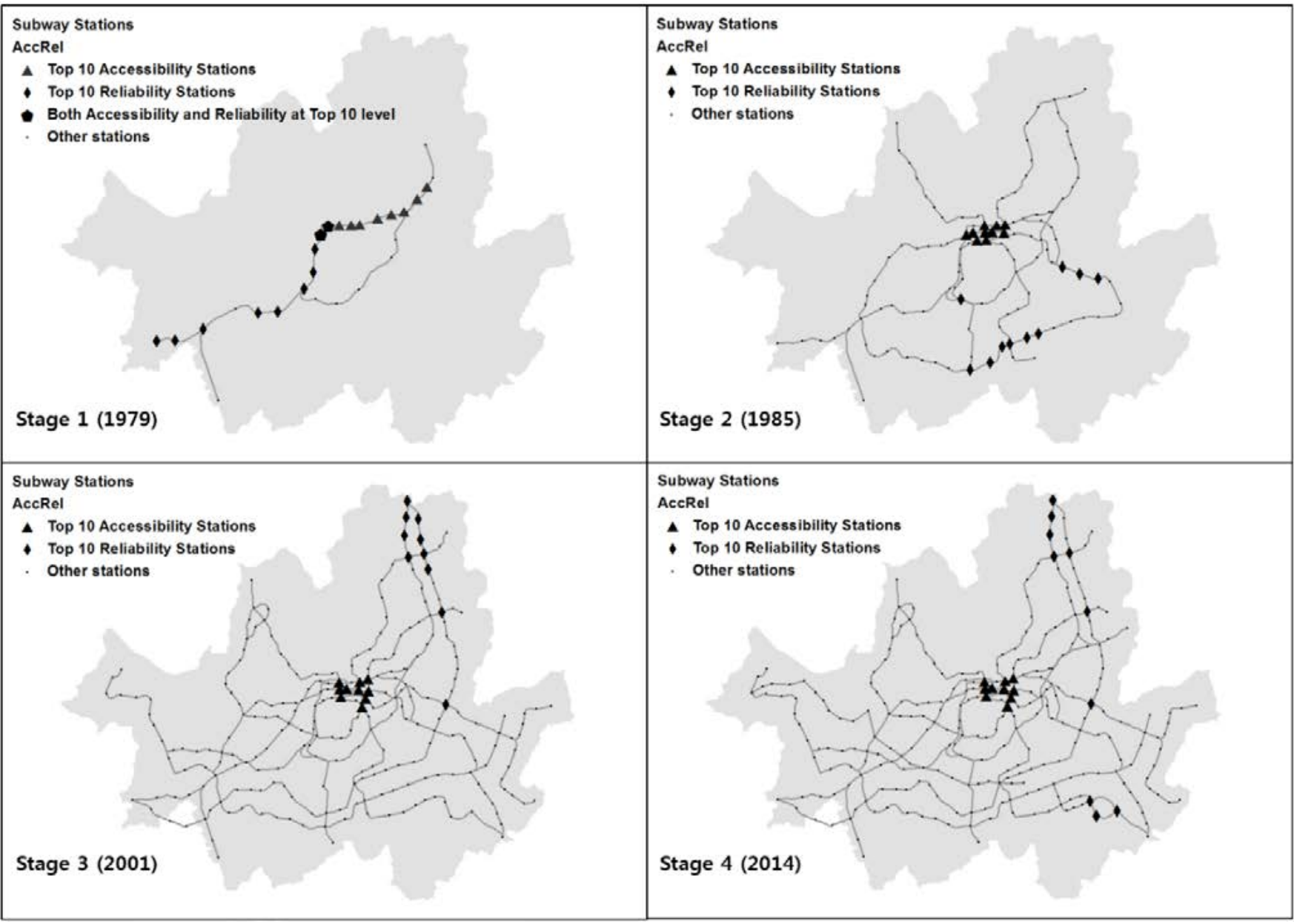

FIGURE 4. Top-10 stations in terms of accessibility and reliability 
A comparison of Figures 5 and 6 highlights how the potential relationship between both measures have manifested geographically over time. To enable comparison between measures and times, the ranges of accessibility and reliability were standardized using $z$-scores, and the surface maps were generated using the Inverse Distance Weighted (IDW) function with higher polynomial functions to the standardized z-score.

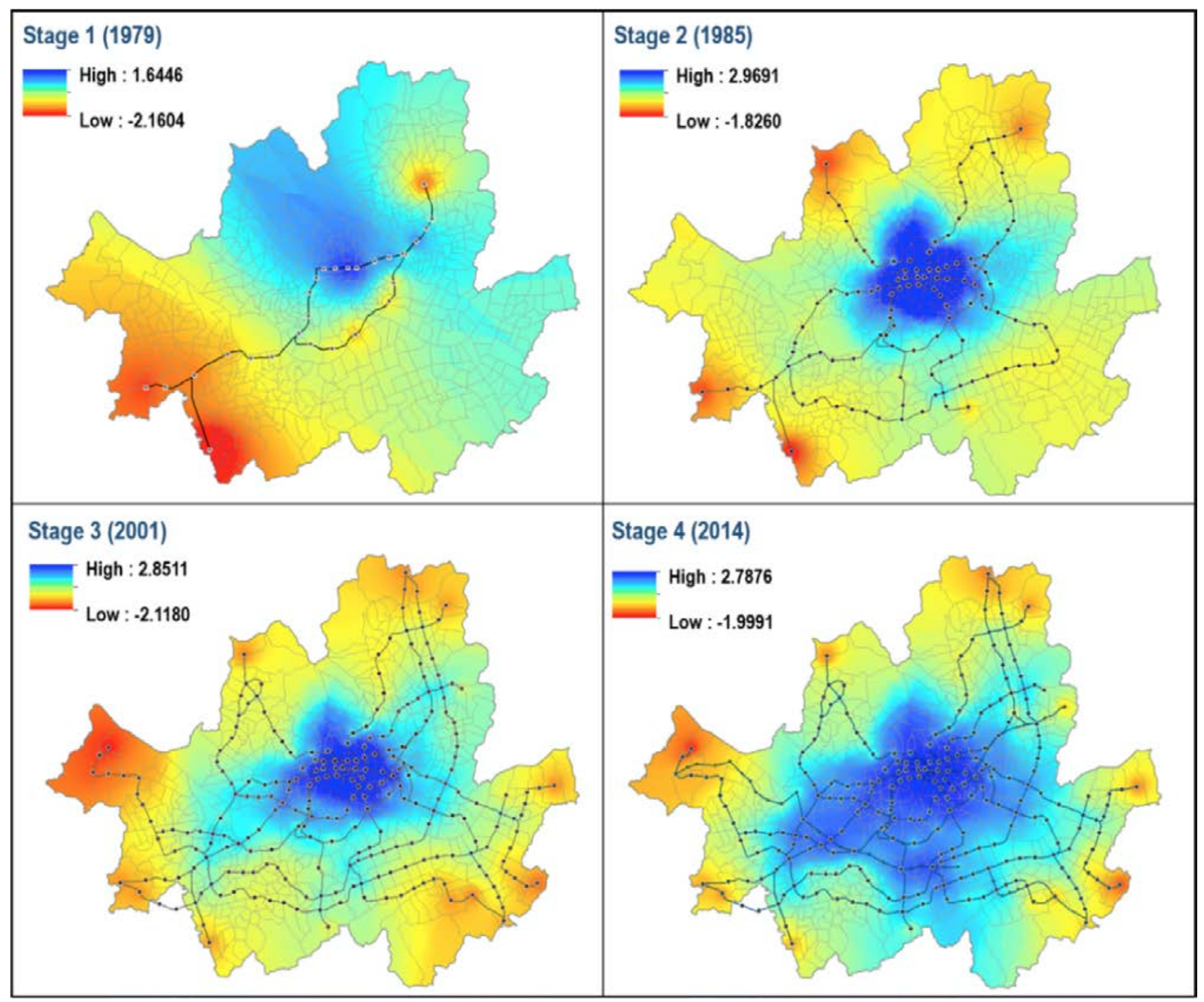

FIGURE 5. Standardized accessibility with evolution of subway system 


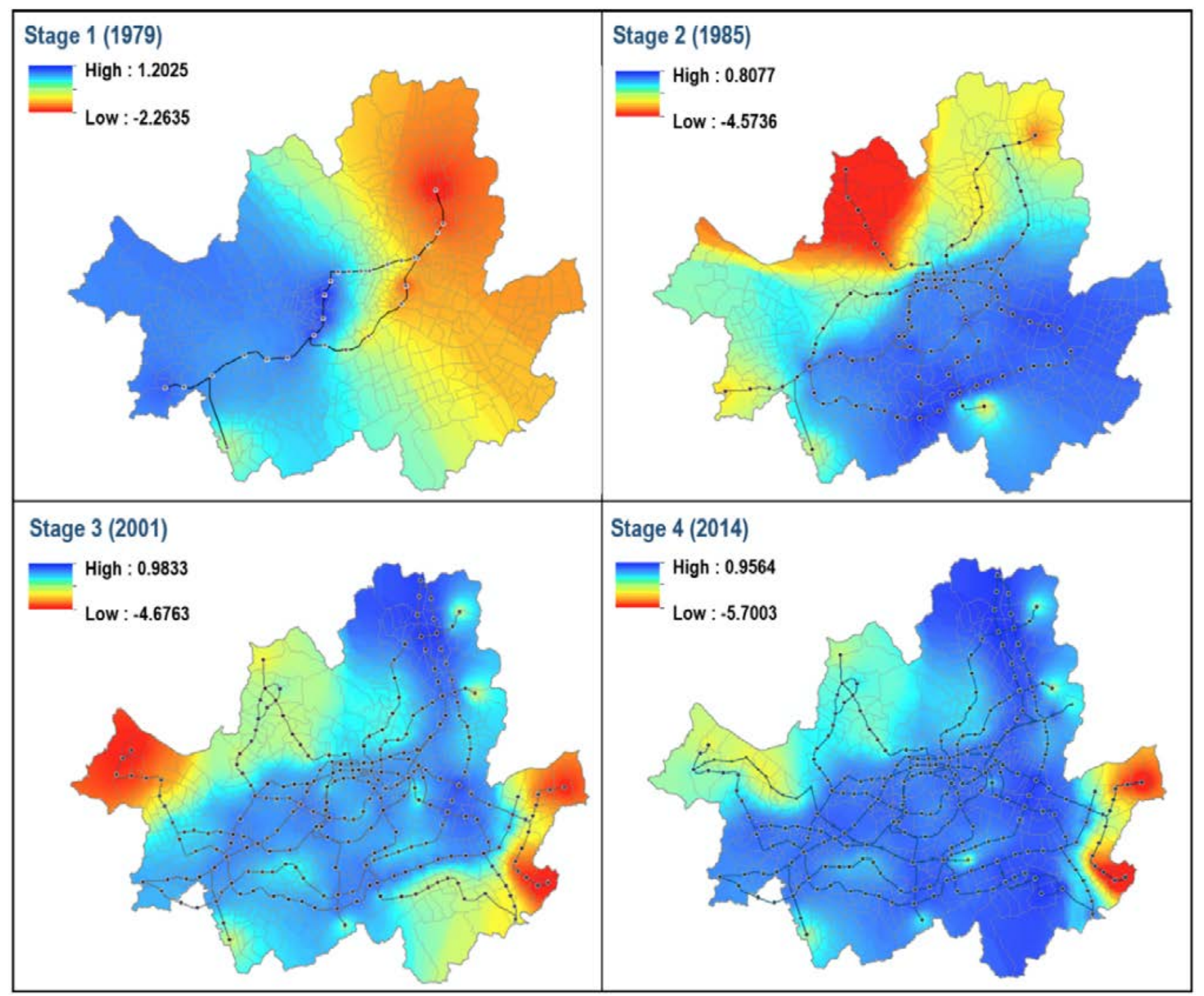

FIGURE 6. Standardized reliability with evolution of subway system

As illustrated in Figure 5, it is noticeable that the blue area, i.e., the high-accessibility area, has expanded as the network has evolved, which was highly predictable given the increasing accessibility average provided in Figure 3 . Notice that the highlyaccessible area identified in stage 1 was the so-called CBD and that the areas has grown, keeping the centralized form until stage 4, where the size of the blue area has increased significantly, covering half of Seoul city in the last stage. During this process, the peripheral areas were left with lower accessibility. This is due to the network expansion strategy, which focused on developing the public transit system from central Seoul toward peripheral areas but ignored connections to improve the accessibility of peripheral areas. As such, the spatio-temporal pattern of the change in accessibility in Seoul supports the argument of Roth et al. (2012) that "a core with branches radiating from it" (p. 2540) is a common feature of various large subway networks. 
In contrast, the spatio-temporal change in reliability measures shown in Figure 5 is similar to the accessibility measurement results overall, but clear distinctions were found in the northern area, where the lines were least connected to the circular line compared to the southern areas, so that their reliability has not been positively enhanced over time. Compared to the accessibility patterns, the high-reliability area has not expanded with a core-periphery form; rather, it appears to have a directional pattern, forming corridors. In the first stage, an east-west contradiction was apparent. However, from stage 2 onwards, the spatial pattern of reliability radically changed: the south-eastern part of Seoul showed a high reliability level as a result of the circular line, then a wide southwest-northeast band appeared with strong reliability levels in stages 3 and 4 due to the added connections within the circular line. Since 2000, these areas have been characterized by an increased number of hub stations; as result, a number of alternative routes are enabled for passengers to travel to the southwest-northeast areas more easily, thereby enhancing nodal reliability for all of Seoul.

The perspectives of both concepts are different, as are their outcomes, although the methods on both sides focus on investigating network performance. Recent studies also imply that a station with high accessibility is not necessarily highly reliable, and vice versa (Li and Kim 2014; Kim et al. 2015). Accordingly, given these results, the evolution of a network could involve the development of different geographical areas in terms of reliability and accessibility, and the geographic representation of the surface indicates how well the public transit system has been developed in terms of balance between spatial opportunity in access and soundness in network operation.

\section{Conclusions and Future Research}

In this study, the spatio-temporal pattern of a subway network was investigated using two traditional network performance measures in relation to the case study of Seoul. The Seoul subway network has expanded quickly but steadily since its first operation, which has resulted in increasing patterns of accessibility and reliability. However, the spatial patterns and the level of maturation do not exactly correspond to each other. Accessibility has consistently improved from the core to peripheral areas, as suggested by other literature. As discussed in the early work by Lee and Lee (1998), highlyaccessible stations were concentrated in the CBD area but spread from the CBD to local areas. On the other hand, reliability improved between stages 1 and 2, but, thereafter, the level of increase was not as impressive as the increase in accessibility as the system entered a mature period, with its improvement pattern being directional. In particular, this result highlights the critical role of the circular line in improving network reliability. Completion of the circular line at stage 2 was not critically important in terms of improving accessibility; however, it was a critical moment for the Seoul subway system in terms of providing high reliability for the whole area to maintain the desired level of reliability for the rest of the stages. As Li and Kim (2014) stated, the first way to improve network performance in a balanced manner is to increase hub stations to provide an increased routing choice of shorter paths and at the same time alternative routes for passengers (even though these may take longer than the single shortest route). 
It should be noted that the results of this study are not universally applicable. Each transit system develops based upon the local context in which it is located. As such, the spatio-temporal patterns found in Seoul's subway system may not be suitable to explain the evolution of different subway systems. However, it is clear that the evolution of the structure of networks involves both a change of network accessibility and network reliability from simple to complicated systems (Kim et al. 2015). In this context, this study contributes to the literature in various ways. First, accessibility and reliability are popularly-used measures in various subjects, but most studies focus only on one such issue at a time. We examined both accessibility and reliability in the case of the evolution of the Seoul subway system, one of the largest and most mature public transit systems in the world, in the context of the distinctive economic development of Seoul. Second, as an analytical framework, the spatio-temporal development pattern of Seoul's subway network was tracked from the beginning to the present day using two different but consistent network measurement methodologies, which were standardized for longitudinal analysis and revealed the areas that benefited more and less in the context of public transport accessibility and reliability. Finally, using two measures at once allows transport policymakers, practitioners, and researchers to have a comprehensive view of the characteristics of the public transit networks in both supply and demand perspectives.

As a future extension of this research, the present analytical framework could be applied to other public transit systems across cities or metropolitan areas, from highlydeveloped networks such as New York and Beijing, through intermediate networks such as Washington DC and Berlin, to small but initial stage networks such as Glasgow and Algiers, for comparative analysis. Furthermore, as suggested by Reggiani (2013), an integrated measure should be developed for better network vulnerability analysis of various forms of rapid transit systems. There is great potential for the two measures used in this study-accessibility and reliability - to be developed into a universal standardized measure for the effective assessment of network resilience, as these measures have been used successfully in transit network system analysis.

\section{References}

Aviation and Railway Accident Investigation Board. 2015. Annual Accident Statistics 2005-2013. http://araib.molit.go.kr.

Allenby, B., and J. Fink. 2005. "Towards Inherently Secure and Resilient Societies." Science, 309(5737): 1034-1036.

Bell, M. G. H., and C. Cassir. 2000. Reliability of Transport Networks. Baldock: Research Studies Press.

Bettencourt, L. M., J. Lobo, K. Helbing, C. Kühnert, and G. B. West. 2007. "Growth, Innovation, Scaling, and the Pace of Life in Cities." Proceedings of the National Academy of Sciences of the United States of America, 104(17): 7301-7306. 
Cervero, R., and M. Duncan. 2002. "Transit's Value-Added Effects: Light and Commuter Rail Services and Commercial Land Values." Transportation Research Record, 1805: 8-15.

Colbourn, C. J. 1987. The Combinatorics of Network Reliability. New York: Oxford University Press.

Cox, A., F. Prager, and A. Rose. 2011. "Transportation Security and the Role of Resilience. A Foundation for Operational Metrics." Transport Policy, 18(2): 307-317.

D’Este, G. M., and M. A. P. Taylor. 2003. "Network Vulnerability: An Approach to Reliability Analysis at the Level of National Strategic Transport Networks." In The Network Reliability of Transport edited by lida, Y., and M. G. H. Bell, 23-44. Oxford: Pergamon-Elsevier.

Dhillon B. S. 2011. Transportation Systems Reliability and Safety. CRC Press.

Garrison, W. L. 1960. “Connectivity of the Interstate Highway System.” Papers and Proceedings of Regional Science Association, 6: 121-137.

Gould, P. R. 1967. "On the Geographical Interpretation of Eigenvalues." Transactions of the Institute of British Geographers, 42: 53-86.

Halden, D., P. Jones, and S. Wixey. 2005. "Accessibility Literature Review." EPSRC FIT Programme Working Paper Series 3, Transport Studies Group, University of Westminster.

Hansen, W.G. 1959. "How Accessibility Shapes Land Use." Journal of the American Institute of Planners, 35(2): 73-76.

Harris, B. 2001. "Accessibility: Concepts and Applications." Journal of Transportation and Statistics, 4(3): 15-30.

Kim, H., C. Kim, and Y. Chun. 2015. "Network Reliability and Resilience of Rapid Transit Systems." The Professional Geographer (doi:10.1080/00330124.2015.1028299).

Kim, J., and M. Zhang. 2005. "Determining Transit's Impact on Seoul Commercial Land Values: An Application of Spatial Econometrics." International Real Estate Review 8(1): 1-26.

Lakshmanan, T. R., and W. P. Anderson. 2002. "A White Paper on Transportation Infrastructure, Freight Services Sector, and Economic Growth." Report prepared for the U.S. Department of Transportation.

Lakshmanan, T. R., and W. P. Anderson. 2005. "Transport's Role in Regional Integration Process." Presented at the OECD Regional Round Table 134.

Lakshmanan, T. R., W. P. Anderson, Y. Song, and D. Li. 2009. "Broader Economic Consequences of Transport Infrastructure: The Case of Economic Evolution in Dynamic Transport Corridors." Report prepared for the Federal Highway Administration, U.S. Department of Transportation.

Lee, K., and H.-Y. Lee. 1998. "A New Algorithm for Graph-Theoretic Nodal Accessibility Measurement." Geographical Analysis, 30(1): 1-14. 
Lee, K., K.-M. Kim, and Y. Song. 2010. "Impacts of Mixed-Use Development and Transportation on Housing Values." Journal of the Economic Geographical Society of Korea 13(4): 515-528.

Li, Y., and H. Kim. 2014. "Assessing Survivability of the Beijing Subway System." International Journal of Geospatial and Environmental Research, 1(1): Article 3. http://dc.uwm.edu/ijger/vol1/iss1/3.

Lucas, K. 2006. "Providing Transport for Social Inclusion within a Framework for Environmental Justice in the UK." Transportation Research A, 40: 801-809.

Matisziw, T. C., A. T. Murray, and T. H. Grubesic. 2009. "Exploring the Vulnerability of Network Infrastructure to Interdiction." The Annals of Regional Science, 43(2): 307321.

McMillen, D. P., and J. McDonald. 2004. "Reaction of House Prices to a New Rapid Transit Line: Chicago's Midway Line 1983-1999." Real Estate Economics, 32(3): 463 486.

Michael, D. T. 2000. “Use On-Time Performance: A Field Study of Subway Service Reliability." New York City Transit Riders Council.

Murray, A. T., and T.H. Grubesic. 2007. Critical Infrastructure: Reliability and Vulnerability. Berlin: Springer-Verlag.

Murray, A. T., T. C. Matisziw, and T. H. Grubesic. 2008. "A Methodological Overview of Network Vulnerability Analysis." Growth and Change, 39(4): 573-592.

Nagurney, A., and Q. Qiang. 2009. Fragile Networks: Identifying Vulnerabilities and Synergies in an Uncertain World. Hoboken, NJ: John Wiley and Sons.

Nicholson, A. J., and E. Dalziell. 2003. "Risk Evaluation and Management: A Road Network Reliability Study." In The Network Reliability of Transport, edited by lida, Y., and M. G. H. Bell, 45-59. Oxford: Pergamon-Elsevier.

Niedzielski, M. A., and E. J. Malecki. 2012. "Making Tracks: Rail Networks in World Cities." Annals of the Association of American Geographers, 102(6): 1409-1431.

Páez, A., D. M. Scott, and C. Morency. 2012. "Measuring accessibility: Positive and Normative Implementations of Various Accessibility Indicators." Journal of Transport Geography, 25: 141-153.

Pucher, J., H. Park, M. H. Kim, and J. Song. 2005. "Public Transport Reforms in Seoul: Innovations Motivated by Funding Crisis." Journal of Public Transportation, 8(5): 41-62.

Reggiani, A. 1998. Accessibility, Trade and Locational Behavior. Aldershot: Ashgate.

Reggiani, A. 2013. "Network Resilience for Transport Security: Some Methodological Considerations." Transport Policy, 28: 63-68.

Roth, C., S. M. Kang, M. Batty, and M. Barthelemy. 2012. "A Long-Time Limit for World Subway Networks." Journal of the Royal Society Interface, 9(75): 2540-2550. 
Schintler, L. A., S. Gorman, R. Kulkarni, and R. Stough. 2007. "Moving from Protection to Resiliency: A Path To Securing Critical Infrastructure." In Critical Infrastructure, edited by Murray, A. T., and T. H. Grubesic, 291-307, Berlin: Springer-Verlag.

Seoul Metropolitan Government (SMG), 2014. Daily Mode Share Statistics.

Song, Y., and H. Kim. 2015. "Evolution of Subway Network Systems, Subway Accessibility and Change of Urban Landscape: A Longitudinal Approach to Seoul Metropolitan Area." International Journal of Applied Geospatial Research, 6(2): 53-76.

Song, Y., K. Lee, W. P. Anderson, and T.R . Lakshmanan. 2012. "Industrial Agglomeration and Transport Accessibility in Metropolitan Seoul." Journal of Geographical Systems, 14(3):299-318.

The Economist. 2013. "Going Underground." January 5.

Tinkler, K. J. 1972. "The Physical Interpretation of Eigenfunctions of Dichotomous Matrices." Transactions of the Institute of British Geographers, 55: 17-46.

Vromans, M. J. C. M., R. Dekker, and L. G. Kroon. 2006. "Reliability and Heterogeneity of Railway Services." European Journal of Operational Research, 172(2): 647-665.

Weinberger, R. R. 2001. "Light Rail Proximity: Benefit or Detriment in the Case of Santa Clara County, California." Transportation Research Record, 1747: 104-113.

Yoo, Y. B., and N. Deo. 1988. "A Comparison of Algorithms for Terminal-Pair Reliability." IEEE Transactions on Reliability, 37: 210-215.

Zhu, S., and M. Levinson. 2012. "Disruptions to Transportation Networks: A Review." In Network Reliability in Practice, edited by Levinson, M. H. L., and M. G. H. Bell, 5-20. New York: Springer.

\section{About the Authors}

DR. HyUn KıM (hkim56@utk.edu) is an assistant professor in the Department of Geography at the University of Tennessee. His research interests include spatial optimization for urban transportation and telecommunications, assessment of network reliability/survivability of spatial network systems, and telecommunications policy.

DR. Yena Song (y.song@chonnam.ac.kr) is an assistant professor in the Department of Geography at Chonnam National University, South Korea. Her research centers on issues such as the economic impacts of transportation networks, sustainable transportation, and public transportation systems in urban area. She is the corresponding author of this article. 